\author{
空間分解X線分光法を用いた高圧ガスパフにおける \\ レーザー生成プラズマの特性評価 \\ 鈴木 将之, 大道 博行*, 酒屋 典之*, Henryk FIEDOROWICZ** \\ Andrzej BARTNIK **, 中山 斌義 \\ 近畿大学大学院 工学研究科電子工学専攻 ( 5 577-8502 大阪府東大阪市小若江 3-4-1) \\ *大阪大学レーザー核融合研究センター（テ 565-0871 大阪府吹田市山田丘 2-6） \\ ** Institute of Optoelectronics, Military University of Technology (Kaliskiego 2, 00-908, Warsaw, Poland)
}

\title{
Characterization of Laser-Produced Plasmas from High Pressure Gas-Puff Using Space Resolved X-Ray Spectroscopy
}

\author{
Masayuki SUZUKI, Hiroyuki DAIDO,* Noriyuki SAKAYA,* Henryk FIEDOROWICZ** \\ Andrzej BARTNIK, ** and Takeyoshi NAKAYAMA \\ School of Science \& Engineering Kinki University, 3-4-1 Kowakae, Higashi-Osaka, Osaka 577-8502, Japan \\ *Institute of Laser Engineering, Osaka University, 2-6 Yamadaoka, Suita, Osaka 565-0871, Japan \\ **Institute of Optoelectronics, Military University of Technology, Kaliskiego 2, 00-908, Warsaw, Poland
}

(Received February 2, 1999)

\begin{abstract}
In order to characterize the interaction process between a high power laser and a high pressure pulsed gas (gas puff), we have studied laser irradiate gas puff targets. A YAG Laser pulse of $10 \mathrm{~ns}$ time duration with intensities of $10^{12} \mathrm{~W} / \mathrm{cm}^{2}$ was used to produce plasmas. We have systematically measured space-resolved $\mathrm{x}$-ray emission spectra in the wavelength range between $8 \mathrm{~nm}$ and $22 \mathrm{~nm}$ for various kind of gases.
\end{abstract}

Key Words: X-ray emission, Laser plasma, Gas puff target

1.はじめに

レーザープラズマからの軟X線放射については,これま で多くの研究があり基礎科学や産業技術にX線源として応

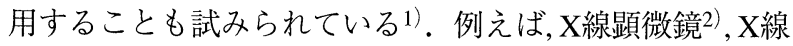
リソグラフィー3) $\mathrm{X}^{3}$ 線ホログラフィー4), X線非破壊検査用 光源などにX線源として用いられている。

このプラズマからのX線放射は, X線源としての用途に加 えてレーザープラズマの相互作用の研究手段として有用 である。すなわちX線を測定対象とすることによりレー ザー照射に伴う物質のイオン化, 電子温度, 電子密度等に 関する詳細な知見を得ることができる，特に高圧ガスパ フターゲット5)を用いると噴出ガス中にクラスター6)が生 じ,クラスターとレーザー光との特異な相互作用を研究す ることもできる。 またプラズマから放出される高エネル ギーイオンも物質改質に応用可能であり高出力レーザー とガスパフターゲットとの相互作用解明は重要でかつ興 味深い研究テーマである.

本論文では, 高圧ガスパフターゲットを用いたときに生 成するレーザープラズマの評価の一環として, 波長域8$20 \mathrm{~nm}$ の軟X線の空間分解測定に関する実験結果について
報告する。

\section{2. 実験方法}

実験は, 大阪大学レーザー核融合研究センターの小型繰 り返しレーザープラズマX線発生装置HIREXを用いて行わ れた ${ }^{7-9)}$. 直径 $52 \mathrm{~cm}$ のステンレス製真空チャンバー内に配

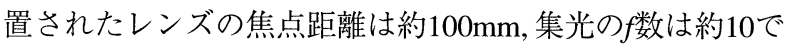

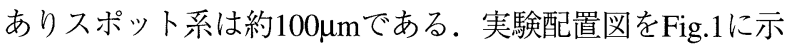
す. Nd:YAGレーザーパルスを高圧ガスパフターゲットに 照射して, 生成するレーザープラズマX線の各波長におけ る空間分解測定を行った。用いたレーザーは, Nd:YAG レーザー(HOYA Continuum社製, YG682)で波長1.06 $\mu \mathrm{m}$, レーザーパルスエネルギーは $0.7 \mathrm{~J}$, ターゲット上での照射 強度約 $10^{12} \mathrm{~W} / \mathrm{cm}^{2}$, パルス幅 $8 \mathrm{~ns}(\mathrm{FWHM})$ であり $10 \mathrm{~Hz}$ の繰り 返し運転が可能である。真空チャンバー内のレーザー集 光位置にガスパフノズルを設置した。レーザー照射の約 200-300 $\mu \mathrm{s}$ 前にノズルの入り口のバルブ(直径 $0.5 \mathrm{~mm}$ )が開 き，ガスがチャンバー内に噴出される。 なおガスの背圧 (Backing pressure)は10気圧でありノズルの約 $0.5 \mathrm{~mm}$ 上の レーザーが照射される位置では約1気圧である10)。これに 


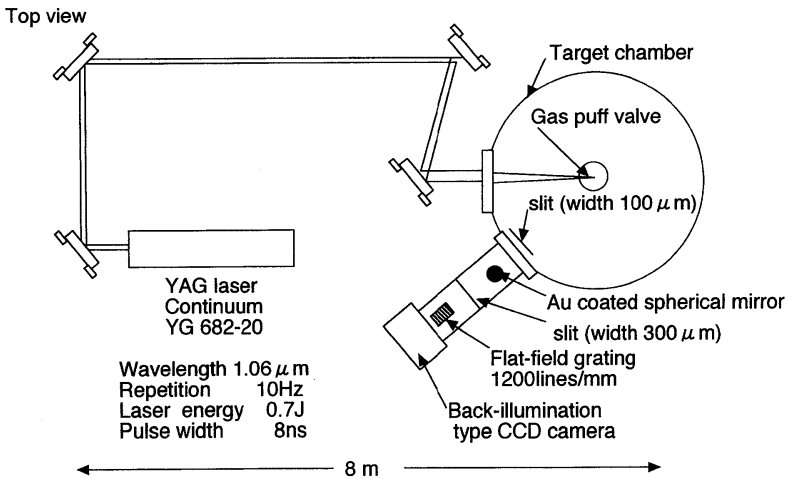

Fig.1 Experimental set up.

よって生成したレーザープラズマを幅 $100 \mu \mathrm{m}$, 長さ $2 \mathrm{~cm}$ の スリットを(ガスパフノズルから $19.5 \mathrm{~cm}$ の位置に設置)平面 結像型斜入射分光器 (1200lines $/ \mathrm{mm}$ )の前に配置し一種のク ロススリットカメラの配置をとって生成したレーザープ ラズマの空間分解測定を行った。この配置での倍率は約5 倍であり幾何光学的なフレネル効果による空間分解能は $120 \mu \mathrm{m}$ である。一方CCDカメラのピクセルサイズは $24 \mu \mathrm{m}$ なので測定系としての分解能は $120 \mu \mathrm{m}$ と評価できる.

測定方法を, Fig.2に示す。斜入射型分光器とターゲット とを結ぶ軸を回転中心にして分光器の回転を調節するこ とによりレーザー照射光軸の垂直方向と光軸方向に分け て空間分解測定を行った. すなわち, 光軸方向の空間分解 測定を行うときには, Fig.2（a)のようにスリットを垂直に して分光器に軟X線を導く．光軸に対して垂直方向の空間 分解測定を行うときには, Fig.2（b)のスリットを光軸方向 に向けて分光器を 90 度回転させて測定を行った。ター ゲットとして使用したガスは, 酸素, クリプトン, キセノン

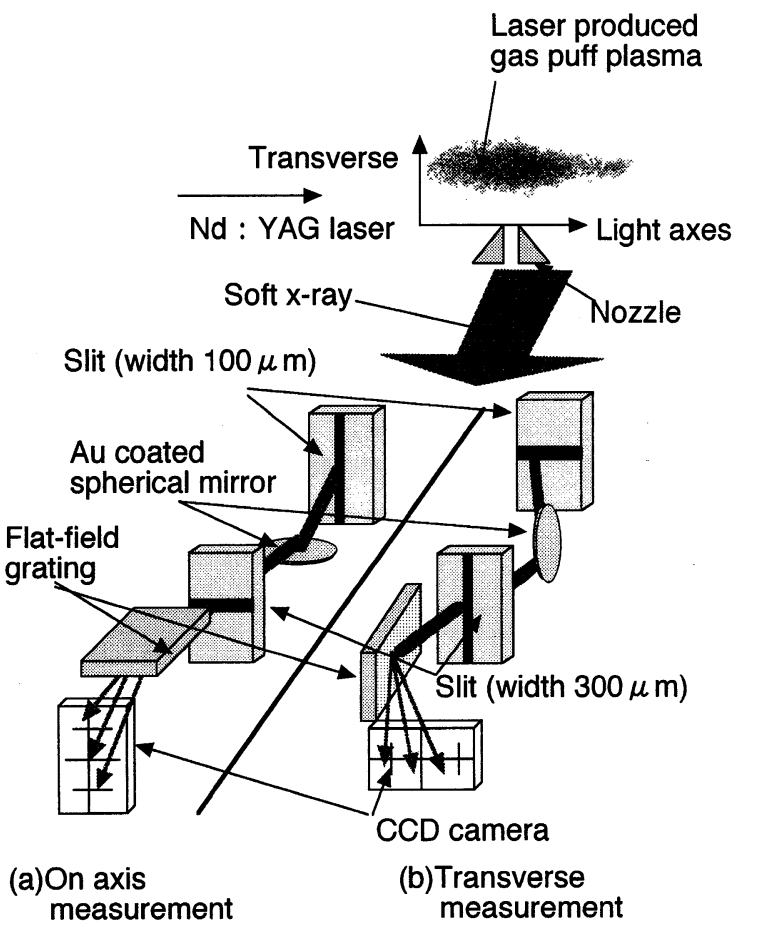

Fig.2 Schematic diagram of the space resolved spectral measurement system.
であった。これらのガスを用いた理由としては, 原子番号 が8, 36, 54でありそれぞれが特徵的なスペクトル構造を有 していることである.すなわち原子番号8番では, 1本ずつ の線スペクトルX線, 36番では線スペクトルの構造を残し つつも多くが重なり合いブロック化し, 54番ではその重な りが一層進み連続スペクトルに近くなっている。また8-20 $\mathrm{nm}$ の波長域内で輝度の高い軟X線放射スペクトルが得ら れ, 精度良くプラズマの特性評価を行いうるからである. すべてのスペクトル測定は背面照射型CCD (Charge Coupled Device) カメラ (Princeton Instruments社製モデルSX-TM/ CCD-1024-TK/1)を用いて行った.

\section{3. 実験結果}

\section{1 酸素プラズマの空間分解測定}

測定結果をFig.3に示す。本論文の光源のサイズは半値 全幅(FWHM)を用いている。光軸方向のスペクトル図の Fig.3-5の (a)の縦軸の下方よりレーザーが照射されてい る。実験結果より波長 $13 \mathrm{~nm}$ 近傍で見られる $\mathrm{Li}$ 様: $1 \mathrm{~s}^{2} 2 \mathrm{~s}-$ $1 \mathrm{~s}^{2} 3 \mathrm{p}$ 遷移の光軸方向のソースサイズは, 約 $520 \mu \mathrm{m}$, 垂直方 向は, 約 $270 \mu \mathrm{m}$ であった。また, 波長 $15 \mathrm{~nm}$ 近傍で見られた Li様: $1 \mathrm{~s}^{2} 2 \mathrm{p}-1 \mathrm{~s}^{2} 4 \mathrm{~d}$ 遷移の光源のサイズは, レーザー照射光軸 に対して光軸方向約 $500 \mu \mathrm{m}$, 垂直方向は約 $280 \mu \mathrm{m}$ であり, 光 軸方向と垂直方向で光源のサイズが大きく異なっている事 がわかった。一方, 波長 $18 \mathrm{~nm}$ 近傍のBe様:2s2p-2s3d遷移か らの放射では光軸方向が $480 \mu \mathrm{m}$, 垂直方向は約 $320 \mu \mathrm{m}$ で あった. 垂直方向のBe様と $\mathrm{Li}$ 様の遷移の光源のサイズを 比較するとLi様の方がイオン価数が高いにもかかわらずサ

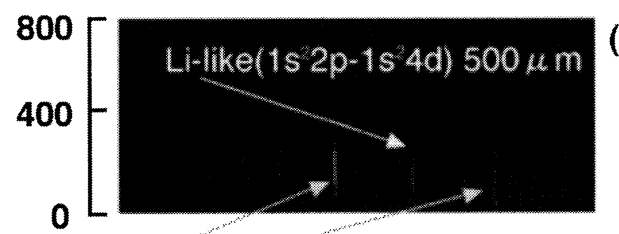

(a)

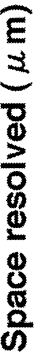

Be-like(2s2p-2s3d) $480 \mu \mathrm{m}$ Li-like $\left(1 s^{2} 2 s-1 s^{2} 3 p\right) 600 \mu m$

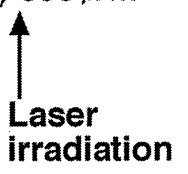

Li-like(1 $\left.\mathrm{s}^{2} 2 \mathrm{~s}-1 \mathrm{~s}^{2} 3 \mathrm{p}\right) 270 \mu \mathrm{m}$

Be-like(2s2p-2s3d) $320 \mu \mathrm{m}$

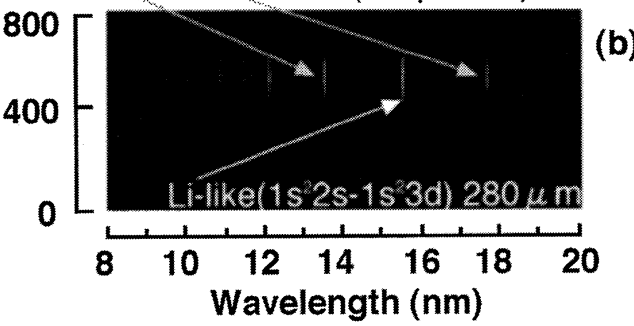

Fig.3 Space resolved spectral images of laser irradiated Oxygen gas puff target. (a) On axis image (co-axial to the incident laser axis). (b) Transverse image (perpendicular to the incident laser axis). 
イズは,ほほ等しいことがわかった。

\section{2 クリプトンプラズマの空間分解測定}

測定結果をFig.4に示す。まず光軸方向とそれに垂直方 向の各遷移からの放射を比べる．Fe様の遷移11) からの光 源サイズは, 光軸方向が約 $330 \mu \mathrm{m}$, 垂直方向は約 $150 \mu \mathrm{m}$ で あった．Co様の遷移からの放射の光源のサイズは光軸方 向が約 $350 \mu \mathrm{m}$, 垂直方向は約 $150 \mu \mathrm{m}$. また $\mathrm{Ni}$ 様の遷移から の放射では, 光軸方向が $430 \mu \mathrm{m}$, 垂直方向は $250 \mu \mathrm{m}$ という結 果が得られた. すなわち Fe様, Co様のサイズは光軸方向, 垂直方向ともにそれぞれ，ほぼ同程度であり，Ni様だけが 他の2つに比べて1.2-1.6倍大きかった。

\section{3 キセノンプラズマの空間分解測定}

測定結果をFig.5に示す．波長16nm近傍でのPd様4d-5p遷 移11)の光源のサイズは光軸方向が約 $430 \mu \mathrm{m}$, 垂直方向は約 $240 \mu \mathrm{m}$ と測定された。また波長 $17 \mathrm{~nm}$ 近傍の $\mathrm{Ag}$ 様 ${ }^{11)}$ 遷移の 光源のサイズとして, 光軸方向が約 $500 \mu \mathrm{m}$, 垂直方向は約 $240 \mu \mathrm{m}$ 得られた。キセノンのスペクトルも酸素, クリプ トンと同様に垂直方向と光軸方向のサイズを見比べてみ ると垂直方向のサイズの方が小さいことがわかった。

\section{4. 考 察}

実験結果よりどのガスにおいても光軸方向と垂直方向 のサイズを比較すると垂直方向のサイズの方が常に小さ いことがわかった. Fig.6にレーザーの集光光学系と発生 ガスパフプラズマの形状を示す。また光軸方向の空間分 解像の位置がスペクトル線により大きくずれていること がわかった. Fig.5 (a)に特に顕著に表れている．図中の下 側がレーザーの入射方向である．波長 $11 \mathrm{~nm}$ から $14 \mathrm{~nm} に か$

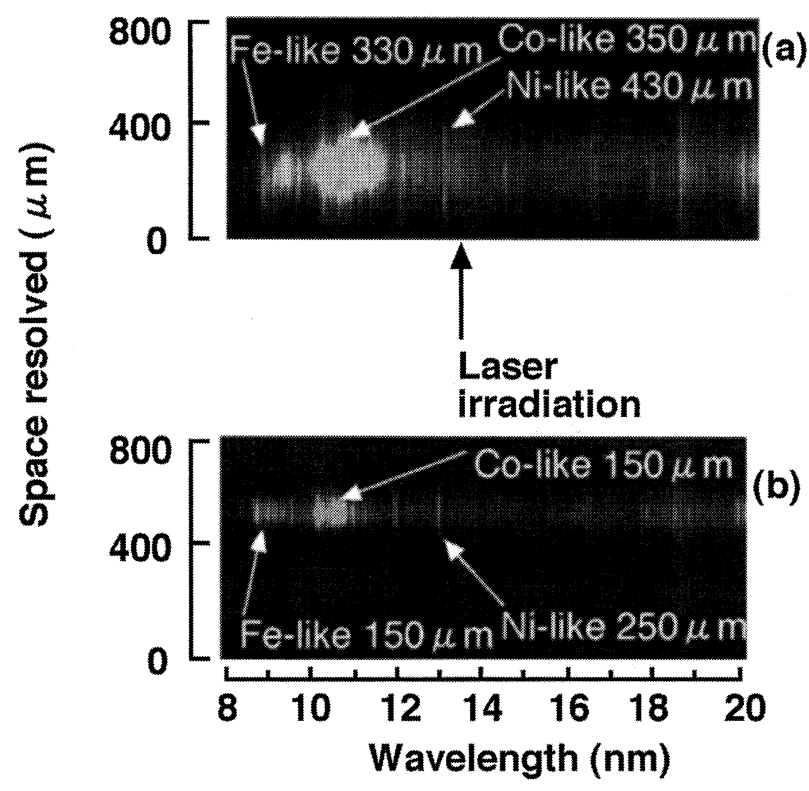

Fig.4 Space resolved spectral images of laser irradiated Krypton gas puff target. (a) On axis image (co-axial to the incident laser axis). (b) Transverse image (perpendicular to the incident laser axis).

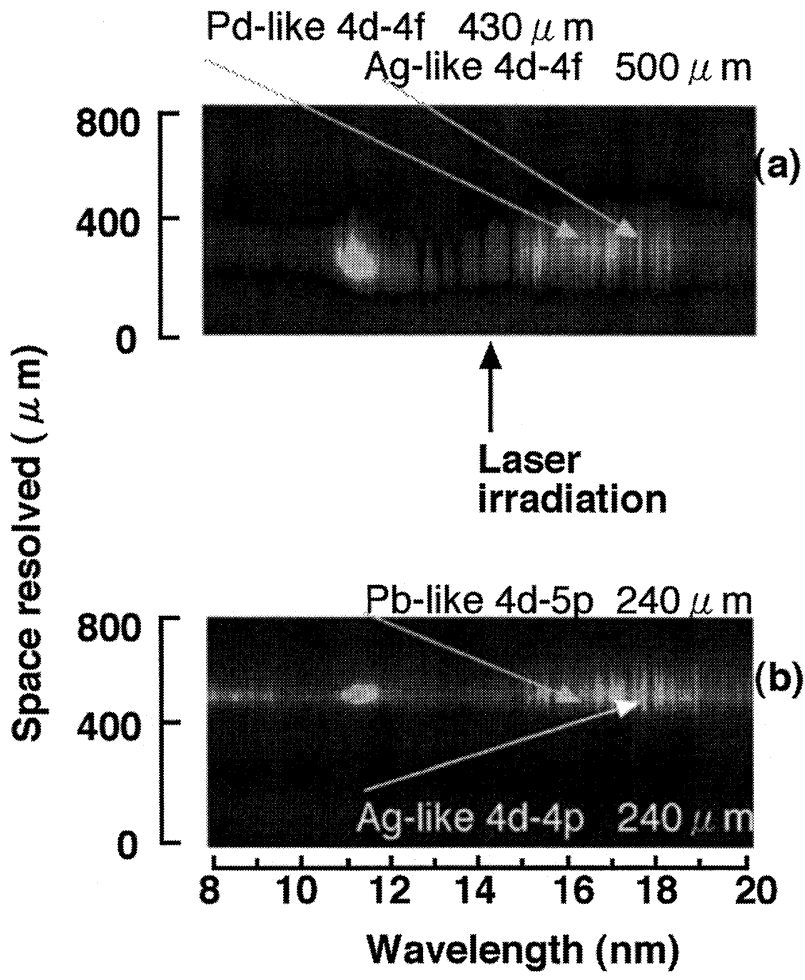

Fig.5 Space resolved images of laser irradiated Xenon gas puff target. (a) On axis image (co-axial to the incident laser axis). (b) Transverse image (perpendicular to the incident laser axis).

けては, 中性キセノンガスによる強い吸収がある。このガ スによりFig.6右側で特に強い吸収を受けていることが Fig.5 (a)よりわかる. 一方光軸に対して垂直方向の空間分 解像は, 各スペクトル線のピーク強度の位置を中心にほぼ 対称となっている。レーザー光がガス噴出領域に集光照 射されると, まずブレークダウンが起こりプラズマ生成が おこる．2方向の空間分解像より本実験条件ではレーリー 長にわたり一様にブレークダウンが起こり，それに引き続 いてプラズマ生成が抢こっていることが示されている。 このとき光軸方向のイオン化の分布はクリプトン, キセノ ンでは一様でないことを実験データーは示している。こ の点に関しては, 時間空間分解測定により,レーザー照射 に伴うイオン化の直接測定が望まれる。このときクラス ター化が起こっているとプラズマ生成が起こるレーザー の強度のしきい值が変わり引き続いて起こるレーザー光

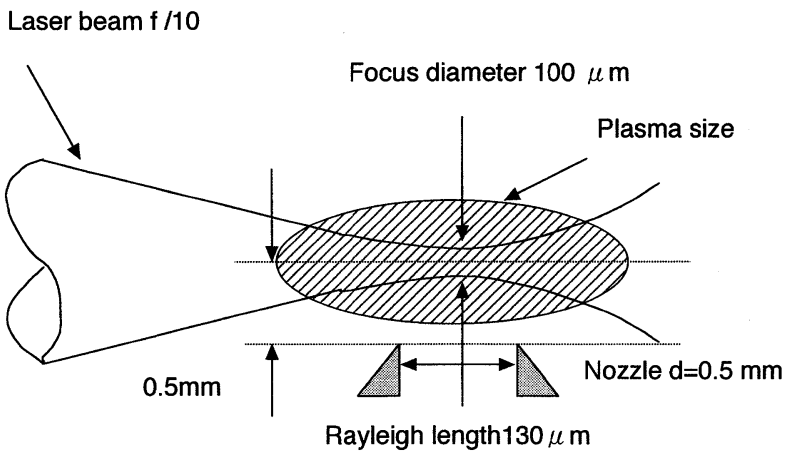

Fig.6 Schematic diagram of a laser created high pressure gas-puff plasma. 
吸収過程が異なる可能性がある。そしていったん,レー ザーエネルギーがプラズマに吸収され始め, プラズマの加 熱が進むと音速でプラズマの膨張が起こりサイズが大き くなってゆくと考えられる，実験結果より原子番号が大 きくなると平均として垂直, 光軸両方向とも光源サイズが 小さくなっている。これは, プラズマ中の音速と同程度の 洁張速度の違いによりプラズマのサイズが決まっている ことを示唆している．すなわち，原子番号が大きくなると イオンの質量数が大きくなり膨張速度が低下し光源の开 イズが小さくなっていると考えられる。ゾーンプレート を用いた波長 $2.87 \mathrm{~nm}$ の単色 2 次元イメージ計測でも同様な 結果が得られている10).

クリプトンをターゲットに用いたときの実験結果でNi 様遷移からの光源のサイズがCo様, $\mathrm{Fe}$ 様遷移のサイズに比 べて約1.2-1.6倍に大きくなった． $\mathrm{Ni}$ 様の基底状態はd款が 充たされ安定配位であり広い範囲の電子密度, 温度領域に 扔いてこのイオン種が存在するため安定でないCo様, $\mathrm{Fe}$ 様 遷移に比べてサイズが大きくなっていると考えられる。

本研究の照射パラメーターでは, キセノン等の高原子番 号物質で顕著に起こると期待されるプラズマ中の放射輸 送による加熱領域の拡大, それによるプラズマサイズの拡 大は, プラズマサイズの原子番号依存性より顕著には起 こっていないと考えられる.

\section{5. 結 論}

高圧ガスパフターゲットにレーザーを照射したときに 生ずるレーザープラズマX線の評価の一環として軟X線源 の空間分解測定を行った。今後時間分解X線測定装置, 短 パルスレーザーを用いて時間的に分解された物理的過程 の解明を行ってゆく必要がある。

\section{謝 辞}

本研究の主要部分は,科学技術振興調整費総合研究「高密 度光の発生と先端的物質制御に関する研究」の一環として 行われた。実験遂行にあたり常に有益な助言, 助力を戴い た加藤 義章氏 (現在日本原子力研究所関西研究所), 村井 健介氏 (大阪工業技術研究所), 大阪大学レーザー核融合研 究センターの関係者に媣く感謝する次第である.

\section{参考文献}

1) 大道 博行：X線ハンドブック (財)電子科学研究所 (1997) p.541.

2) J. Kirz and H. Rarback: Rev. Sci. Instrum. 56 (1985) 1.

3) H. Kinoshita, K. Kurihara, Y. Ishii, and Y. Torii: J. Vac. Sci. Technol. B7 (1989) 1648.

4) I. C. E. Turcu, I. N. Ross, M. S. Schulz, H. Daido, G. J. Tallents, J. Krishnan, L. Dwivedi, and A. Hening: J. Appl. Phys. 73 (1993) 8081.

5) H. Fiedorowicz, A. Bartnik, Z. Patron, and P. Parys: Appl. Phys. Lett. 62 (1993) 2778.

6) O. F. Hagena and W. Obert: J. Chem. Phys. 56 (1972) 5.

7) G. M. Zeng, H. Daido, T. Togawa, H. Aritome, M. Nakatsuka, K. Nishihara, and S. Nakai: J. Appl. Phys. 69 (1991) 7460.

8) G. M. Zeng, H. Daido, K. Murai, Y. Kato, M. Nakatsuka, and S. Nakai: J. Appl. Phys. 72 (1992) 335.

9) G. M. Zeng, H. Daido, T. Nishikawa, H. Takabe, S. Nakayama, H. Aritome, K. Murai, Y. Kato, M. Nakatsuka, and S. Nakai: J. Appl. Phys. 75 (1994) 1923.

10) H. Fiedorowicz, A. Bartnik, M. Szczurek, H. Daido, N. Sakaya, V. Kmetik, Y. Kato, M. Suzuki, M. Matsumura, J. Tajima, T. Nakayama, and T. Wilhein: to be published in Opt. Commun.

11) J. Reader, N. Acquista, and V. Kaufman: J. Opt. Soc. Am. $B 8$ (1991)

12) J. Blackburn, P. K. Carroll, J. Costello, and G. O'Sullivan: J. Opt. Soc. Am. 173 (1983) 10 